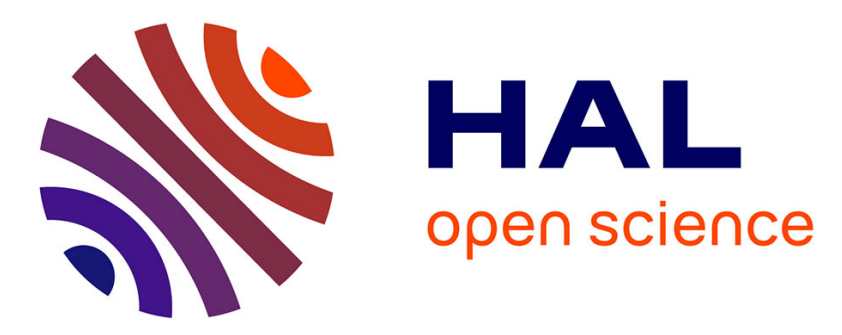

\title{
Brain morphometry predicts individual creative potential and the ability to combine remote ideas
}

David Bendetowicz, Marika Urbanski, Clarisse Aichelburg, Richard Levy, Emmanuelle Volle

\section{- To cite this version:}

David Bendetowicz, Marika Urbanski, Clarisse Aichelburg, Richard Levy, Emmanuelle Volle. Brain morphometry predicts individual creative potential and the ability to combine remote ideas. Cortex, 2017, 86, pp.216 - 229. 10.1016/j.cortex.2016.10.021 . hal-01449698

\section{HAL Id: hal-01449698 \\ https: / hal.sorbonne-universite.fr/hal-01449698}

Submitted on 30 Jan 2017

HAL is a multi-disciplinary open access archive for the deposit and dissemination of scientific research documents, whether they are published or not. The documents may come from teaching and research institutions in France or abroad, or from public or private research centers.
L'archive ouverte pluridisciplinaire HAL, est destinée au dépôt et à la diffusion de documents scientifiques de niveau recherche, publiés ou non, émanant des établissements d'enseignement et de recherche français ou étrangers, des laboratoires publics ou privés. 


\section{Brain morphometry predicts individual creative potential and the ability to combine remote ideas}

David Bendetowicz $^{* \text { a,b,c,d }}$, Marika Urbanski* ${ }^{\text {a,b,c,d,e }}$, Clarisse Aichelburg ${ }^{\text {a,b,c,d }}$, Richard Levy a,b,c,d,f, and Emmanuelle Volle ${ }^{\text {a,b,c,d,g }}$

*Equally contributed to this work.

Submission to the special issue: "Is a *single* brain model sufficient?"
a. Inserm, U 1127, F-75013, Paris, France
b. CNRS, UMR 7225, F-75013, Paris, France
c. Sorbonne Universités, UPMC Univ Paris 06, UMR S 1127, F-75013, Paris, France
d. ICM, FrontLab, Hôpital Pitié Salpêtrière, 47, bd de l'hôpital, 75013 Paris
e. Hôpitaux de Saint-Maurice, Medicine and Rehabilitation Department, 94410 Saint- Maurice, France
f. AP-HP, Hôpital de la Salpêtrière, Behavioural Neuropsychiatry Unit, 75013 Paris, France.
g. ICM, CENIR, Paris, France

Corresponding author:

Emmanuelle Volle: emmavolle@gmail.com

FrontLab - ICM

Hôpital Pitié Salpêtrière, 47, bd de l'hôpital, 75013 Paris

Authors information

David Bendetowicz: davidbendetowicz@hotmail.fr

ICM, FrontLab, Hôpital Pitié Salpêtrière, 47, bd de l'hôpital, 75013 Paris

Marika Urbanski: marika.urbanski@gmail.com

Hôpitaux de Saint-Maurice, Medicine and Rehabilitation Department, 94410 Saint-Maurice, France 
Clarisse Aichelburg: caichelburg@gmail.com

ICM, FrontLab, Hôpital Pitié Salpêtrière, 47, bd de l'hôpital, 75013 Paris

Current address: ICN, Alexandra House 17 Queen Square, London Wc1n 3ar, UK

Richard Levy: richard.dock2@gmail.com

AP-HP, Hôpital de la Salpêtrière, UNPC, batiment Paul Castaigne, 75013 Paris, France 


\title{
Brain morphometry predicts individual creative potential and the ability to combine remote ideas
}

\begin{abstract}
For complex mental functions such as creative thinking, inter-individual variability is useful to better understand the underlying cognitive components and brain anatomy. Associative theories propose that creative individuals have flexible semantic associations, which allows remote elements to be formed into new combinations. However, the structural brain variability associated with the ability to combine remote associates has not been explored. To address this question, we performed a voxel-based morphometry study and explored the anatomical connectivity of significant regions. We developed a Remote Combination Association Task adapted from Mednick's test, in which subjects had to find a solution word related to three cue words presented to them. In our adaptation of the task, we used free association norms to quantify the associative distance between the cue words and solution words, and we varied this distance. The tendency to solve the task with insight and the ability to evaluate the appropriateness of a proposed solution were also analysed. Fifty-four healthy volunteers performed this task and underwent a structural MRI. Structure-function relationships were analysed using regression models between grey matter volume and task performance. Significant clusters were mapped onto an atlas of white matter tracts. The ability to solve the task, which depended on the associative distance of the solution word, was associated with structural variation in the left rostrolateral prefrontal and posterior parietal regions; the left rostral prefrontal region was connected to distant regions through long-range pathways. By using a creative combination task in which the semantic distance between words varied, we revealed a brain network centred on the left frontal pole that appears to support the ability to combine information in new ways by bridging the semantic distance between pieces of information.
\end{abstract}

\section{Keywords:}

Creativity, semantic associations, rostral prefrontal, frontal pole, morphometry 


\section{Introduction}

Complex mental functions may be difficult to study because they often rely on ill-defined cognitive components and are associated with high inter-individual variability in performance on tasks assessing such functions. Creative ability is one of these complex functions. Interindividual variability can nevertheless be a useful source of information to better understand the cognitive components of complex functions and the underlying brain anatomy (Kanai \& Rees, 2011). Mednick proposed that creativity results from "the forming of associative elements into new combinations which either meet specified requirements or are in some way useful. The more mutually remote the elements of the new combination, the more creative the process or solution" (Mednick, 1962). Mednick developed the Remote Associates Test (RAT), to test this theory. In this task, three unrelated cue words are presented, and the subject has to provide a fourth word related to all three cue words (e.g., "rat, cottage, blue" leads to the solution word "cheese"). The construct validity and reliability of this task has been shown in previous studies (Chermahini, Hickendorff, \& Hommel, 2012; Mednick, Mednick, \& Jung, 1964; Mednick, 1962). Mednick hypothesized that creative people have broader and more flexible semantic associations allowing them to generate more original and numerous responses and to connect remote concepts (Mednick, Mednick, \& Jung 1964). This hypothesis - or more generally, the role of associative processing in creativity - has been supported by several studies (Benedek, Könen, \& Neubauer, 2012; Brown, 1973; Mednick, et al., 1964) and partly by Benedek and Neubauer (Benedek \& Neubauer, 2013), who indicated that creative people may not have a particular associative hierarchy but have higher associative fluency and produce more uncommon word associations in a continuous association task than less creative people. Findings from a computational approach (Kenett, Anaki, \& Faust, 2014) confirmed that creative individuals have a richer and more flexible associative network than less creative individuals. In other words, creative abilities appear to be related to particular cognitive traits, allowing remote semantic associations. This variability in cognitive traits may be supported by structural differences that can be revealed by neuroimaging morphometry methods (Fink et al., 2013).

A few voxel-based morphometry (VBM) studies have identified a set of brain regions whose structure varied positively or negatively with creative achievement and with creativity assessments (Abraham, 2013; Benedek et al., 2013; Chen et al., 2014; Fink et al., 2013; Gansler Moore, Susmaras, Jerram, Sousa \& Heilman, 2011; Jauk, Neubauer, Dunst, Fink, \& 
Benedek, 2015; Jung, Segall, et al., 2010; Jung, Grazioplene, Caprihan, Chavez, \& Haier, 2010; Jung \& Haier, 2013; Kühn, Ritter, Müller, Baaren, Brass, \& Dijksterhuis, 2014; Li et al., 2015; Takeuchi et al., 2010a, 2010b; Zhu, Zhang, \& Qiu, 2013). The most explored category of creativity tasks is probably divergent thinking tasks (Guilford, 1950; Torrance, 1972). Divergent thinking is an open-ended approach characterized by the generation of unusual ideas through the exploration of many solutions with no goal of finding the "correct" one. However, to the best of our knowledge, the structural brain variability associated with the individual ability to generate and combine words, as examined by the RAT, has not been explored.

The RAT has been employed in a few studies that used other neuroimaging techniques such as functional MRI and EEG, and its cerebral correlates remain poorly understood. Brain activation associated with the RAT has been reported in right anterior temporal regions, temporo-parietal junction and other posterior temporal regions (Jung-Beeman et al., 2004; Kounios et al., 2006; Kounios \& Beeman, 2014) and/or in the anterior cingulate, prefrontal, inferior parietal, and parieto-occipital regions (Anderson, Anderson, Ferris, Fincham, \& Jung, 2009; Jung-Beeman et al., 2004; Kounios et al., 2006; Razumnikova, 2007; Sandkühler \& Bhattacharya, 2008; Subramaniam, Kounios, Parrish, \& Jung-Beeman, 2011) and share similarities with the brain regions recruited during other creativity tasks (Arden, Chavez, Grazioplene, \& Jung, 2010; Aziz-Zadeh, Kaplan, \& Iacoboni, 2009; Gonen-Yaacovi, de Souza, Levy, Urbanski, Josse, \& Volle, 2013; Jung, 2013; Sawyer, 2011). Most neuroimaging studies have focused on the brain correlates of the insight phenomenon that is elicited by the RAT (Aziz-Zadeh et al., 2009; Dietrich \& Kanso, 2010; Jung-Beeman et al., 2004; Kounios et al., 2006; Martindale \& Mines, 1975; Subramaniam et al., 2011). Insight refers to the sudden awareness of the solution to a problem (i.e., the "Aha!" or "Eureka!" phenomenon) and is accompanied by little or no conscious access to the processing leading up to that solution (Bowden, Jung-Beeman, Fleck, \& Kounios, 2005; Kounios \& Beeman, 2014; Topolinski \& Reber, 2010; Weisberg, 2013). Functional imaging studies using the RAT and comparing insight vs. non-insight solving (Aziz-Zadeh et al., 2009; Jung-Beeman et al., 2004; Kounios et al., 2006) showed different brain correlates than another study (Anderson et al., 2009), which compared successful to unsuccessful trials. Therefore it remains difficult to draw a clear picture of the cerebral correlates associated with the cognitive components of the RAT. In particular, the brain correlates associated with individual abilities to solve the RAT are unknown. 
In a broader context of creative performance, a recent meta-analysis of functional imaging studies revealed that various creativity tasks were associated with shared brain networks (Gonen-Yaacovi et al., 2013). Creativity-related regions included the caudal lateral prefrontal cortex (PFC), the rostral PFC, the dorsomedial PFC and the inferior parietal cortex. These findings were replicated and extended by other meta-analyses (Boccia, Piccardi, Palermo, Nori, \& Palmiero, 2015; Wu et al., 2015). Psychological studies have shown that individuals vary in the ability to generate and combine ideas, and to solve the RAT (Benedek \& Neuebauer, 2013; Kenett et al., 2014; Mednick, 1962). Whether the regions or networks active during creative task performance in functional imaging also have structural properties that support individual creative abilities is an important unaddressed question. A qualitative divergence in the results obtained from morphometric and functional imaging approaches was highlighted in a recent meta-analysis on creativity (Wu et al., 2015), and can be explained by several factors. For instance, functional neuroimaging of creativity typically have explored brain regions shared by all participants, while both creative abilities and the strategies used to perform creativity tasks vary between people. Functional imaging studies have classically relied on the subtraction approach, in which the choice of the control condition may have impacted the results. However, when it occurs, the convergence of the results from functional imaging and morphometry approaches may strengthen the conclusions that can be drawn about the brain regions involved in creativity.

To test the hypothesis that brain networks involved during creative performance may also support and relate to individual creative abilities, we performed a VBM study with an anatomical a priori based on functional imaging findings. The a priori volume of interest was defined from a meta-analysis of functional neuroimaging studies that reported the brain correlates of creativity tasks (Gonen-Yaacovi et al., 2013). The meta-analysis included studies that used various creativity tasks, as the functional neuroimaging studies that used the RAT were not numerous enough to be analysed alone. The resulting map showed the set of regions associated with the cognitive processes shared by diverse creativity tasks and was used as a volume of interest. In this volume of interest, VBM analyses correlated regional brain volume to performance on a new creative combination task (Combination association task or CAT) adapted from Mednick's task. In the CAT task, we quantitatively varied the semantic distance between the cue words and the solution word. This task manipulation allowed us to better estimate the ability of the participants to generate and combine word associates as a function of their semantic distance. In addition, we explored anatomical connectivity between the 
significant VBM clusters using a track-wise analysis based on a diffusion-based atlas of brain connections (Rojkova, Volle, Urbanski, Humbert, Dell'Acqua, \& Thiebaut de Schotten, 2015).

\section{Methods}

\section{Participants}

Fifty-seven right-handed native French speakers aged from 22 to 75 years old were recruited by online announcement via a research platform (http://expesciences.risc.cnrs.fr/). A large age range was chosen for this study to include a group of unselected participants with sufficient variability to represent the general population. The advantages of this approach have been previously discussed (Aichelburg, Urbanski, Thiebaut de Schotten, Humbert, Levy, \& Volle, 2016; Colom, Jung, \& Haier, 2007; Goh, Bansal, Xu, Hao, Liu, \& Peterson, 2011; Grogan, Green, Ali, Crinion, \& Price, 2009; Haier, Jung, Yeo, Head, \& Alkire, 2004). The participants were healthy adults with no history of neurological or psychiatric disorders and no cognitive complaints. The inclusion criteria required the absence of neurological or psychiatric medical history, psychoactive substance abuse and MRI contra-indications. The exclusion criteria included the presence of cognitive impairments, as assessed using a translated version of the Mini Mental State Examination (Folstein, Folstein, \& McHugh, 1975), the presence of semantic disorders as assessed by short French versions of a drawing naming task and of the Pyramid and Palm Tree test (Merck et al., 2011), and the presence of MRI abnormalities suggestive of small vessel disease or an evolving neurological disease. Millimetric T1weighted and diffusion weighted images were examined by a neuroradiologist. The neuropsychological and radiological data were carefully screened to exclude pathologies. Subjects with cognitive impairments or MRI pathological abnormalities were excluded. One participant was excluded because of impaired semantic performance and two because of MRI abnormalities. Fifty-four individuals (27 females) were therefore included in the analyses. The participants' characteristics are reported in Table 1. All subjects provided written informed consent and were paid for their time. The local ethics committee approved the study.

\section{Cognitive assessment: the Combined Associative Task (CAT)}




\section{Conception of the task}

We built a new verbal task adapted from Mednick's RAT (Mednick, 1962), in which subjects were required to find a word related to all three cue words that were presented to them when there was no obvious link between these cue words. In our adaptation of the task, we introduced three main novelties. 1) We used free association norms to quantify the betweenword associative distance (association strength). We used these association norms to verify that the cue words used in each trial were not related, and we quantified the mean associative distance between the cue words and the solution word(s) for each trial; 2) Based on the hypothesis that the more remote the elements to combine, the more creative the process (Mednick, 1962), we varied the semantic distance between the written cue words and the solution word(s) and measured this variation based on the association norms (Debrenne, 2011); 3) To complement the classic solving phase of the task, we introduced an "evaluation" phase. In the evaluation phase, a test word was proposed to the participant, who was asked whether this test word was a correct solution to the problem. This evaluation phase assessed the ability to recognize if a given word met the associative and combinatorial requirements of the task. The ability to recognize relatedness between distant words is thought to be linked with creative abilities (Mednick, Mednick, \& Jung, 1964; Vartanian, Martindale, \& Matthews, 2009). Finally, because this task is also considered an insight problem solving task, the individual tendency to solve the task with insight (solution coming to mind suddenly and without effort) was estimated by collecting subjective reports of these "eureka moments" on a trial-by-trial basis, as has been done previously (e.g., Kounios \& Beeman, 2014).

Overall, each trial of our experimental CAT task was composed of three phases: a solving phase during which the participants tried to solve the trial and generate a possible solution; an insight phase during which insight or a eureka moment was subjectively reported for each trial; and an evaluation phase during which the participants evaluated the relevance and correctness of a given test word as a solution.

\section{Construction of the material based on measures of semantic distance/strength}

Triplets of cue words of variable semantic distance with their solution were created based on free association norms in French. We used the associative frequency between two words as a measure of semantic distance, and we refer to this measure as "association strength". Free association norms in the French population were available through a published database (Debrenne, 2011) available online (http://dictaverf.nsu.ru/). The measured association strength (or frequency) quantifies the proportion of subjects who produced the word B when 
they were given the word A in a free word association task (for instance, if 383 of 538 participants responded "cat" when they were presented the word "dog", then the association strength was $383 / 538 * 100=71)$. We selected from the database measures of association strengths obtained from at least 450 adult native French speakers. Ambiguous words such as words corresponding either to an adjective or to a conjugated form of a verb were avoided. We used association norms measured from free generation tasks instead of word cooccurrences in text corpus (such as latent semantic analysis, which has been used before; Green, Cohen, Raab, Yedibalian, \& Gray, 2015; Smith, Huber, \& Vul, 2013) because this type of measurement appeared closer to our task condition, in which the participants were required to generate a word based on its associations with cue words, and may better capture free word associations (De Deyne, Kenett, Anaki, Faust, \& Navarro, In Press).

Based on this normative associative strength, we built 72 cue word triads, providing 72 trials in the CAT. Each triad was built so that the cue words were not related to each other but shared one (or a few) semantic associate(s), according to the free association norms. We computed the average association strength between the three cue words and the solution word. Some triads had several possible solution words (35 triads had 2 solution words, 17 had 3 solution words, 8 had 4 solution words, 4 had 5 solution words, 3 had 6 solution words and 1 had 7 solution words). In these cases, the mean association strength between the cue words and the solution words were summed because each solution word was considered a correct response. The mean association strength of the 72 trials was $9.13(\mathrm{SD}=7.49)$, and the median was 7.

We classified the trials according to the median of the association strength; trials with mean association strength greater than the median (>7) were classified as "close CAT" trials $(\mathrm{n}=36)$, while those with a mean association strength less than the median were classified as "distant CAT" trials $(n=36)$. For instance, a close CAT trial was "rue" (street) - "campagne" (countryside) - "centre" (centre), the solution of which was "ville" (city), the mean association strength was 16.65 (averaging 20.38 (street-city), 19.77 (countryside-city) and 9.80 (centre - city). A distant CAT trial was "pont" (bridge) - "social" (social) - "attacher" (to tie), the solution of which was "lien" (link), and the mean associative strength was 3.32. The characteristics of the close and distant CAT trials are provided in Table 2. As expected, close and distant CAT trials differed significantly with respect to the mean association strength between the cue words and the solution words.

The close and distant CAT solution words did not differ significantly in their mean written lexical frequency computed with Lexique 3.80 (http://www.lexique.org) (New, 
Pallier, Ferrand, \& Matos, 2001; New, Pallier, Brysbaert, \& Ferrand, 2004) (Table 2). This open French database is based on a large corpus of recent written literature and film subtitles and has been used in many publications. We averaged the lexical frequency of words and corresponding lemmas found in this database for the solution words, response words and test words.

Because it has been shown that individuals perform poorly on the RAT when they are biased to consider high-frequency candidate answers (Gupta, Jang, Mednick, \& Huber, 2012), we examined the mean lexical frequency of the incorrect responses of the participants and compared it with the lexical frequency of correct responses (i.e., the solution words).

As associative steepness may play a role in word generation and in CAT solving, we controlled for the average steepness of the cue words in each triad. Steepness describes the property of a word to evoke one associate much more frequently than any other one. Steepness was calculated as the ratio between the association strength of the second and the first associates of each cue word. For instance, the most frequent associate of "dog" is "cat" with an associative frequency of 71 , the second most frequent associate of "dog" is "animal" with an associative frequency of 4.8. The steepness is the ratio between these two associative frequencies and equals $71 / 4.8=14.8$. The steepness of the cue words did not differ between close and distant CAT trials (Table 2).

Additional material was elaborated for the evaluation task, which required a test word that was evaluated by the participants as a correct solution or not. The test words were equally distributed between valid (36 valid trials in which the test word was a solution word associated with all three cue words) and invalid (36 trials in which the test word was not related to all three cue words). Mean lexical frequency did not differ significantly between valid and invalid test words (respectively, $174.7 \pm 305.7$ and $136.2 \pm 147.9$ occurrences per million; $\mathrm{U}=607.0, \mathrm{~ns})$.

\section{Experimental procedure (Figure 1)}

The participants were seated comfortably in front of a computer screen. The examiner explained the general design and the instructions for the three phases of the task: the solving, eureka and evaluation phases. At the beginning of the task, the instructions were displayed on the screen without a time limit. To ensure the subjects understood the instructions correctly, they completed 10 practice trials, and repetitions of the instructions were provided when needed. Each trial was composed of three phases in the following order. 
Solving phase. The participants were presented with a set of three unrelated cue words that were arranged in a triangle on the screen (Figure 1). They were asked to give a unique word that was related to all three cue words. The subjects were aware that the response could be a noun, a verb or an adjective but not a proper noun or a compound word. The triad was displayed on the screen until the participants produced a response, within a time limit of 30 seconds. A darker background appeared 2 seconds before the end of the display to warn the participants that time was up. Response times were recorded on the computer by button press, and response words were given orally. The examiner wrote down the subjects' answers.

Eureka phase. Five hundred milliseconds after the participant gave his/her answer, a new screen appeared and displayed the word "Eureka?". The subjects pressed the keyboard letter "V" if their previous response word had come to mind spontaneously and suddenly indicating a subjective "Aha" experience. They pressed the keyboard letter "N" otherwise. The participants had 5 seconds to respond. Response types and reaction times were registered.

Evaluation phase. Five hundred milliseconds after the subject had answered the Eureka question, a new screen appeared. The same cue word triad was displayed again, along with a test word in the centre of the triangle. The participant was asked to determine whether the test word was valid (i.e., related to each of the cue words) or invalid (i.e., not a possible solution to the trial). The subject had 10 seconds to respond by pressing distinct keyboard letters: "V" for valid or "N" for non-valid. Response types and reaction times were recorded.

After a two second inter-trial interval, a new triad was displayed, and the same sequence of solving, eureka, and evaluation phases occurred until the 72 trials were completed. Close and distant trials were mixed during the testing session, and the order of all trials was randomized between participants.

The CAT was programmed using MeyeParadigm version 1.7 (e(ye)Brain Inc., 2009) running on a PC.

\section{Measured variables}

Solving phase: The percentage of correct responses (i.e., the percentage of trials solved) was measured and analysed (CAT-solving). To measure creative ability as an associative process depending on the semantic distance/association strength, an index (CATindex) was calculated as the difference between performance on close and distant trials, divided by the mean performance in both conditions. The CAT-index represents the difference between close and distant trials in terms of the percentage of the total performance 
and reflects the ability of a participant to solve distant trials as well as close trials. A lower index thus reflects better associative combination and creative abilities.

Eureka phase: The percentage of trials correctly solved with a subjective "Eureka" feeling was also analysed (CAT-eureka).

Evaluation phase: Only trials that were unsolved in the preceding solving phase were considered in the evaluation phase so that the CAT-solving score would not bias the CATeval score. In other words, CAT-eval measured the correct evaluation of a test word (percentage of correct validation of a valid word as the solution or of correct rejection of an invalid word) as a percentage of the number of trials that had not been spontaneously solved during the solving phase.

Reaction times for correct responses in the solving and evaluation phases were also analysed (CAT-solving-RT and CAT-eval-RT).

\section{Other creative thinking assessments}

All participants completed the Abbreviated Torrance Test for Adults (ATTA) as an evaluation of divergent thinking (Goff \& Torrance, 2002). The ATTA includes one verbal and two figural activities. Two independent raters (MU and DB) evaluated the test according to the Torrance manual instructions. High inter-raters reliability was observed (intraclass correlation $($ ICC $)=.920 ; \mathrm{p}<.001)$ for the total score. The scores from both raters were averaged to obtain the final score. The total score (ATTA index), the originality subscore (measuring the unusualness of the production of each participant) and the fluency subscore (measuring the quantity of production of each participant) were analysed.

The subjects also completed the Creative Achievement Questionnaire (CAQ) to estimate real-life creative production (Carson, Peterson, \& Higgins, 2005).

\section{Neuropsychological assessment}

All participants underwent a neuropsychological examination. Executive functions were assessed by the Frontal Assessment Battery; FAB) (Dubois, Slachevsky, Litvan, \& Pillon, 2000), the Stroop word-colour test (Stroop, 1935), and semantic and lexical fluency tasks (Cardebat, Doyon, Puel, Goulet, \& Joanette, 1990). Semantic knowledge was assessed using short French versions of a naming test and a semantic matching test (Merck et al., 2011).

VBM Study: Image Acquisition and Analysis

\section{MRI Acquisition}


The subjects underwent a high-resolution T1-weighted structural MRI on a Siemens 3-Tesla VERIO TIM system equipped with a 32-channel head coil. An axial 3-dimensional MPRAGE dataset covering the whole head was acquired for each participant with the following parameters: 176 slices, voxel resolution $=1 \times 1 \times 1 \mathrm{~mm}, \mathrm{TE}=2.98 \mathrm{~ms}$, TR $=2300 \mathrm{~ms}$, and flip angle $=9^{\circ}$.

\section{Preprocessing}

We used the VBM8 toolbox (http://dbm.neuro.uni-jena.de/vbm/) running on SPM8 (Wellcome Department of Imaging Neuroscience, London, UK) for MRI data preprocessing (http://dbm.neuro.uni-jena.de/vbm8/vbm8-manual.pdf). Data processing was similar to the procedures used in Aichelburg et al., (2016) on the same sample of participants.

Spatial normalization to the Montreal National Institute template (MNI152) was performed using the high-dimensional Dartel normalization (Ashburner, 2007). The MRI images were segmented into grey matter (GM), white matter (WM) and cerebrospinal fluid (CSF) according to the new version of the unified segmentation method (Ashburner \& Friston, 2005). Normalized and modulated GM images were computed with an isotropic voxel size of $1.5 \times 1.5 \times 1.5 \mathrm{~mm}^{3}$ and using the default estimation parameters, as described in the VBM8 Toolbox Manual. Modulation compensates for regional volume changes caused by normalization. The "normalized non-linear modulation only" option was used, allowing us to analyse relative differences in regional GM volume corrected for individual brain size. Evaluation of the homogeneity of covariance between individuals served as a quality check.

Images with less than -2 standard deviations were visually examined, but none of them had to be excluded. In addition, all normalized images were visually inspected and compared with the template using frontal anatomical landmarks by an expert neurologist (E.V.). Finally, smoothing using a Gaussian kernel of $8 \mathrm{~mm}$ full-width half maximum was applied to the normalized and modulated images to account for slight variations between individual normalizations and to allow for parametric statistics. The resulting smoothed, modulated, and normalized GM datasets were used for statistical analyses.

\section{VBM Statistical Analysis}

We ran multiple regression analyses in SPM8 between GM volume and the CAT variables. Separate models were utilized for CAT-solving, CAT-eval and CAT-eureka. Age, years of education, gender, and individual total GM volume were included as covariates in the linear regression models. Global values of total GM volume were extracted and calculated from the 
get_totals script (available on http://www0.cs.ucl.ac.uk/staff/g.ridgway/vbm/get_totals.m). Threshold masking was set to .2 to include in the analysis only voxels with sufficient signal. For each regression analysis, we applied a Small Volume Correction (SVC) for multiple comparisons (Ridgway, Henley, Rohrer, Scahill, Warren, \& Fox, 2008). For the SVC analyses, we used a priori-defined volumes corresponding to the results identified in a previous meta-analysis of functional imaging studies on creativity (Gonen-Yaacovi et al., 2013). This coordinate-based meta-analysis evaluated the "inter-experiment" reliability of the involvement of brain regions in creativity tasks. To ensure an optimal result, the main metaanalysis map was re-ran with the last update of the Activation Likelihood Estimation software (ALE v2.3.6; http://brainmap.org/ale/cli.html; Eickhoff, Bzdok, Laird, Kurth, \& Fox, 2012; Eickhoff, Laird, Grefkes, Wang, Zilles, \& Fox, 2009; Laird et al., 2005; Turkeltaub, Eickhoff, Laird, Fox, Wiener, \& Fox, 2012), with a cluster correction for multiple comparisons ( $<$ < .05), as used in Gonen-Yaacovi et al., 2013. The resulting map is shown on Figure 2 and is very similar to the one obtained previously; all current significant clusters were superimposable to those published using an older version of the software (Gonen-Yaacovi et al., 2013).

To place a priori results in context, exploratory whole-brain VBM analyses were also performed at a more permissive uncorrected threshold, and are provided in the supplementary material.

\section{Track-wise analysis}

We mapped the significant VBM clusters onto tractography reconstructions of white matter pathways obtained from a group of healthy controls (Rojkova et al., 2015). We measured the probability that the tract would connect each VBM cluster (Thiebaut de Schotten et al., 2014) using Tractotron software, which is part of the BCB toolkit (http://.brainconnectivitybehaviour.eu). Tractotron automatically computes the overlap of each cluster with the atlas tracts and provides the probability for each voxel to belong to a specific tract in the MNI referential. We only considered tracts that intersected each cluster with a probability above the chance level (probability $>.5$ ).

\section{Statistical analysis}

Statistical analyses were performed using SPSS version 22.0 (IBM Corp., 2010) for behavioural statistics and post-hoc correlation analyses. Non-parametric tests were used when the assumption of normality was not met. 


\section{Results}

\section{Behavioural analysis (Tables 1 and 2)}

Mean accuracy and RTs for the psychometric measures are reported in Tables 1 and 2.

\section{Effects of CAT characteristics}

CAT-solving was significantly positively correlated with the mean association strength between the cue words and the solution word $\left(\mathrm{r}_{\mathrm{s}}=.407, \mathrm{p}<.001\right)$, as was CAT-eureka $\left(\mathrm{r}_{\mathrm{s}}=\right.$ $.257, \mathrm{p}=.029)$ but not CAT-eval $\left(\mathrm{r}_{\mathrm{s}}=.044, \mathrm{p}=.712\right)$. CAT-solving did not correlate with the steepness of the cue words $\left(\mathrm{r}_{\mathrm{s}}=-.014, \mathrm{p}=.904\right)$ or with the mean lexical frequency of the solution words $\left(\mathrm{r}_{\mathrm{s}}=.020, \mathrm{p}=.870\right)$, indicating that the steepness of the cues and the lexical frequency of the word to be found did not bias the results. In addition, the mean lexical frequency of the correct and incorrect responses of the participants did not meaningfully differ (137.9 \pm 24.3 and $139.6 \pm 106.3$ occurrences per million, respectively, Wilcoxon $Z=-$ 1.950), indicating that the error response words were not more frequent words than the solution words, i.e., that errors were not biased towards more frequent words.

\section{Subjects' performance}

In the solving phase, the participants had significantly lower CAT-solving performance and slower CAT-solving-RTs for the distant compared to the close trials (Table 2) and less accurately evaluated the test words in the evaluation phase (CAT-eval score). Close CAT trials elicited more "Eureka" reports than the distant CAT trials.

Correlations within and between the creativity test scores are shown in Supplementary Table 1. CAT-solving correlated significantly with CAT-eval but not with CAT-eureka. The subject group had a mean ATTA index score of 66.2, corresponding to a lower-middle creative ability. We observed significant partial correlations between the CAT-index and the CAQ score $(\mathrm{p}=.006)$ and between the CAT-index and the ATTA originality subscore $(\mathrm{p}=$ .045) when controlling for education, age and gender. Correlations between the CAT-index and the ATTA index and ATTA fluency score were not significant. No significant correlations were found between CAT-solving, CAT-eureka or CAT-eval and the other creativity scores. 


\section{VBM analysis (Table 3; Figure 3)}

The VBM analysis revealed correlations between CAT-solving and the GM volume of brain structures, as indicated in Table 3. The SVC analysis based on the meta-analysis of functional imaging findings showed negative correlations between CAT-solving and GM volume in the left rostrolateral prefrontal cortex (rlPFC) and in the left inferior parietal lobule (IPL) (Figure 3). No significant SVC corrected results were found for CAT-eureka and CAT-eval scores. In other words, the tendency to solve the task with insight, and the ability to recognize conjoint associative relatedness between words, i.e., to evaluate the appropriateness of a given word to meet the requirements of each problem, were not associated with a regional structural variability. Exploratory and uncorrected results are provided in supplementary material.

To better characterize the functional profile of the CAT-solving related regions, and explore whether they are related to the semantic distance that was manipulated in our experiment, we regressed the GM volume in both regions against CAT-index. CAT-index measures the ability to solve more creative (distant) trials and to engage into a more creative process. Entering both rlPFC and IPL regions into the same model allowed to examine which of these structures may be particularly related to creative abilities. The mean GM volume within the rlPFC and IPL clusters was extracted using FSL (http://fsl.fmrib.ox.ac.uk/fsl/fslwiki/) and entered in a multiple regression analysis with CAT-index as the dependent variable, and mean GM volume of the rlPFC cluster, mean GM volume of the IPL clusters, as well as age, education, and gender as independent variables. The predictors accounted for approximately $22.4 \%$ of the variance $(\mathrm{F}(5,48)=2.77, \mathrm{p}=.028)$. CAT-index was predicted by GM volume in the left rlPFC region $($ Beta $=.391, \mathrm{p}=.018)$ whereas the other predictors made no significant contribution to the model.

\section{Track-wise analysis (Table 4)}

The probabilities of the white matter tracts (computed with the BCB toolkit) to connect to the VBM clusters identified in the previous analyses are provided in Table 4. Among the clusters associated with CAT-solving performance, the left rlPFC was the most anatomically connected region, with a high probability of connection to six different tracts within the left hemisphere, including the anterior thalamic radiations, the fronto-marginal tract, the frontostriatal projections, the Inferior Fronto-Occipital fasciculus, the Uncinate Fasciculus, the Superior Longitudinal fasciculus branch 3 (SLF 3). The rlPFC and IPL clusters shared some connections with the SLF3. 


\section{Discussion}

We built a new experimental paradigm, CAT, based on Mednick's task and theory of association, and varied the semantic distance between words to better capture creative ability. Our behavioural findings showed that the ability to solve distant as well as close trials (CATindex) correlated significantly with scores on other creativity tools measuring divergent thinking (ATTA) and creative production in real life (CAQ). To the best of our knowledge, this is the first adaptation of the RAT in which semantic distances were controlled and varied to study the ability to combine distant elements of knowledge. Despite the relatively small sample size and Pearson $r$ coefficients, the identified correlations indicate a correct construct validity of the CAT-index relative to other creativity measures. These findings suggest that the creative potential measured by the CAT-index is related to real-life creativity. Implementing this task manipulation and measures in future uses of the RAT may refine its value for assessing creativity. In our French version of the task - as in the German version (Abraham, Beudt, Ott, \& Yves von Cramon, 2012) - there were several correct solutions for some of the trials. This differs from the English version and from Bowden's compound-RAT (Bowden \& Jung-Beeman, 2003), in which only one solution is expected. How language impacts the solving of remote association tasks and the effect of semantic distance on the solving of these problems remain open questions.

The current VBM analyses revealed that performance in solving the CAT (CATsolving) according to word remoteness depended on the morphometry of brain structures in prefrontal and parietal regions that have been associated with creative performance in a metaanalysis of functional imaging results (Gonen-Yaacovi et al., 2013). Variation in individual performance was associated with variation in GM volume in left-lateralized regions in the rlPFC and IPL. Our SVC approach does not allow any conclusion outside the regions identified as reliably involved in creativity tasks in functional neuroimaging, according to Gonen-Yaacovi et al., (2013). Nevertheless, the regions we observed have also been highlighted in previous morphometry studies on creativity that used divergent thinking or creative achievement measures (Chen et al., 2014; Jung, Segal, et al., 2010; Jung, 2013). The current results are also in agreement with patient studies that showed significant impairments on creativity tasks in patients with damage to frontopolar or parietal regions (Abraham, 
Beudt, et al., 2012; de Souza et al., 2010; 2014; Shamay-Tsoory, Adler, Aharon-Peretz, Perry, \& Mayseless, 2011).

The tractography results showed that the left rlPFC might be connected to the left IPL via the SLF 3, suggesting a role for a fronto-parietal network in creative abilities, as suggested by previous findings (Abraham, Pieritz, et al., 2012; Abraham, Beudt, et al., 2012; Benedek et al., 2013; Chavez-Eakle, Graff-Guerrero, García-Reyna, Vaugier, \& Cruz-Fuentes, 2007; Cousijn, Zanolie, Munsters, Kleibeuker, \& Crone, 2014; Jung, 2013; Fink et al., 2009; Fink, Grabner, Gebauer, Reishofer, Koschutnig, \& Ebner, 2010; Fink et al., 2015), including findings that related creative abilities to white matter structures (Jung, Grazioplene, et al., 2010; Takeuchi et al., 2010b). The current results additionally suggest that the left rlPFC may have a unique status among the creativity-related regions captured by the Gonen-Yaacovi et al meta-analysis, which were mostly left-sided. First, GM volume in the left rlPFC (but not in the IPL) predicted more creative task solving (CAT-index). Second, Tractotron analysis identified several tracts connecting this region to various other posterior parietal, temporal and subcortical regions, suggesting high connective properties. These anatomical and functional properties put the rlPFC in a strategic position to combine and integrate distinct and disparate elements of information. The CAT task requires the subjects to consider and integrate several conceptual associations to find the solution, which likely involves relational comparisons and integration, as in analogical reasoning (Green et al., 2010; Green, Kraemer, Fugelsang, Gray, \& Dunbar, 2012; Krawczyk, 2012). The observed connective properties of the left rlPFC may indeed suggest that its connections with regions involved in semantic memory (including the IPL; Abraham, 2014; Benedek et al., 2013; Binder, Desai, Graves, \& Conant, 2009; Price, Bonner, Peelle, \& Grossman, 2015; Vigneau et al., 2010) and with posterior association cortices may allow the integration of distant elements of information as required in the CAT task (Benedek et al., 2013; Christoff et al., 2001; Genovesio, Wise, \& Passingham, 2014; Green et al., 2012; Hobeika et al., 2016; Parkin, Hellyer, Leech, \& Hampshire, 2015; Ramnani \& Owen, 2004; Reynolds et al., 2006). Furthermore, our structural findings can also be compared to functional connectivity findings. Recent functional connectivity studies have shown that several brain networks, including the frontoparietal control network, interact during creative thinking (Beaty, Benedek, Wilkins, et al., 2014; Beaty et al., 2015; Beaty, Benedek, Silvia, \& Schacter, 2016; Chen et al., 2014; 2015; Takeuchi et al., 2012; Wei et al., 2012), and that the left rlPFC may be an important connective node within and between networks. The structural and functional connective 
properties of this region underlying creative abilities are an interesting avenue for future research.

It is notable that while the current results converge with a set of functional imaging and morphometry findings that used various creativity tasks, they only partially cover the regions previously reported in the few functional imaging that used the RAT. The brain correlates of the CAT-solving score included other areas previously observed in functional imaging of the RAT, including the posterior parietal region (Anderson et al., 2009; AzizZadeh et al., 2009; Subramanian et al., 2011). However, due to our SVC approach, some of the regions that have previously been associated with insight during RAT performance were not explored in the current study, i.e., the right anterior temporal, parieto-temporal (JungBeeman et al., 2004, Kounios et al., 2006; Aziz-Zadeh et al., 2009), and anterior cingulate regions (Anderson et al., 2009).

Finally, the physiological bases underlying the regional variations in GM volume that we observed remain to be clarified. Our findings show that the macroscopic correlates of creative abilities showed negative correlations between GM volume and performance. Despite the large age range of the participants, it is unlikely that aging may have biased the results, as our analyses were corrected for age and total GM volume, and CAT-solving did not significantly correlate with age. Furthermore, if there were an effect of age, a lower GM volume would be associated with poorer CAT performance (a positive correlation). Negative correlations (or both negative and positive correlations) between performance and GM volume or thickness have been reported in many studies (Kanai \& Rees, 2011), including studies exploring creative abilities (Chen et al., 2014; Jauk et al., 2014; Jung, 2013; Jung, Grazioplene, et al., 2010; Jung, Segall, et al., 2010; Jung, Wertz, Meadows, Ryman, Vakhtin, $\&$ Flores, 2015). Yet, the microscopic variability that underlies macroscopic variations in GM volume is not clearly understood (Kanai \& Rees, 2011; Eriksson et al., 2009). A possible interpretation of the current results may be that good performers may have experienced a more efficient synaptic pruning or cortical myelination in fronto-parietal regions (Dumontheil, Houlton, Christoff, \& Blakemore, 2010; Krawczyk et al., 2010).

\section{Conclusions}

In this study, we related creative potential, as reflected by the ability to combine remote elements of information, with brain morphometry. Based on Mednick's theories, our 
CAT task allowed us to explore individual variability in the ability to bridge associative distances in an integrated manner to generate a combined solution. CAT-index assessed the effect of the remoteness of the elements to combine and appeared to be a valid measure of creativity. Within an a priori volume of interest defined by previous functional imaging results, the ability to combine remote elements was associated with structural variations in left rostral frontal and posterior parietal regions. The left rlPFC region was found highly connected to other cortical and subcortical regions through long-range pathways. This network may support the ability to combine information in new ways, by bridging semantic distances between individual pieces of information. These results suggest a structural network supporting creative abilities in which the left rlPFC may act like an "integration core" for the integration and combination of various types of information from distributed systems in the brain. The current study adds a novel finding to the existing literature by showing interindividual structural variations in specific nodes of the functional networks that have been associated with creative performance.

Further studies are needed to clarify the specific role of these regions and how they interact when an individual is engaged in this type of creativity task and when the problem is solved through insight versus when it is not.

Finally, if the CAT task captures several cognitive components, creativity is a multidimensional capacity that is unlikely to be fully captured by a single test. For instance, creative abilities may vary due to individual variability in cognitive control, attention capacities, personality, cognitive style, and affective traits or states, which may also influence CAT problem solving performance and could be related to individual variation in brain structures in future studies. 


\section{Figure legends}

Figure 1. Time course of a CAT trial. In the resolution phase (a), the subjects were asked to find a fourth word related to all three cue words. In this example, the solution word is "air". Once the subjects gave their response, they were then asked if the answer came to mind spontaneously without effort in the Eureka phase (b). Finally, in the evaluation phase, a test word was displayed together with the cue words, and the subjects were asked to decide whether the test word was a solution word (i.e., was related to all of the cue words) (c). In this example, the test word is invalid with no associative relation with the cue words.

Figure 2: Creativity map resulting from the meta-analysis of functional imaging studies and used as volume of interest in the SVC analysis. The creativity map results from a previous coordinate-based meta-analysis of functional imaging (Gonen-Yaacovi et al., 2013) based on 44 experiments that used creativity tasks.

Figure 3: Significant clusters associated with CAT-solving performance in the VBM analysis are shown in green. 


\section{Acknowledgements}

This work was supported by the 'Agence Nationale de la Recherche' [grants number ANR09-RPDOC-004-01, EV], the "Fondation pour la recherche medicale" [grant numbers: FDM20150632801 and DEQ20150331725], and the "Societe Française de Neurologie" (DB). The research leading to these results received funding from the programme "Investissements d'avenir" ANR-10-IAIHU-06. 


\section{References}

Abraham, A. (2013). The promises and perils of the neuroscience of creativity. Frontiers in Human Neuroscience, 7, 246. http://doi.org/10.3389/fnhum.2013.00246

Abraham, A. (2014). Creative thinking as orchestrated by semantic processing vs cognitive control brain networks. Frontiers in Human Neuroscience, 8, 95. http://doi.org/10.3389/fnhum.2014.00095

Abraham, A., Beudt, S., Ott, D. V. M., \& Yves von Cramon, D. (2012). Creative cognition and the brain: Dissociations between frontal, parietal-temporal and basal ganglia groups. Brain Research, 1482, 55-70. http://doi.org/10.1016/j.brainres.2012.09.007

Abraham, A., Pieritz, K., Thybusch, K., Rutter, B., Kröger, S., Schweckendiek, J., et al. (2012). Creativity and the brain: Uncovering the neural signature of conceptual expansion. Neuropsychologia, 50(8), 1906-17. http://doi.org/10.1016/j.neuropsychologia.2012.04.015 Aichelburg, C., Urbanski, M., Thiebaut de Schotten, M., Humbert, F., Levy, R., \& Volle, E. (2016). Morphometry of left frontal and temporal poles predicts analogical reasoning abilities. Cerebral Cortex, 26(3):915-32. http://doi.org/10.1093/cercor/bhu254

Anderson, J. R., Anderson, J. F., Ferris, J. L., Fincham, J. M., \& Jung, K.-J. (2009). Lateral inferior prefrontal cortex and anterior cingulate cortex are engaged at different stages in the solution of insight problems. Proceedings of the National Academy of Sciences, 106(26), 10799-10804. http://doi.org/10.1073/pnas.0903953106

Arden, R., Chavez, R. S., Grazioplene, R., \& Jung, R. E. (2010). Neuroimaging creativity: A psychometric view. Behavioural Brain Research, 214(2), 143-156. http://doi.org/10.1016/j.bbr.2010.05.015

Ashburner, J. (2007). A fast diffeomorphic image registration algorithm. NeuroImage, 38(1), 95-113. http://doi.org/10.1016/j.neuroimage.2007.07.007

Ashburner, J., \& Friston, K. J. (2005). Unified segmentation. NeuroImage, 26(3), 839-851. http://doi.org/10.1016/j.neuroimage.2005.02.018

Aziz-Zadeh, L., Kaplan, J. T., \& Iacoboni, M. (2009). “Aha!”: The neural correlates of verbal insight solutions. Human Brain Mapping, 30(3), 908-16. http://doi.org/10.1002/hbm.20554

Beaty, R. E., Benedek, M., Silvia, P. J., \& Schacter, D. L. (2016). Creative cognition and brain network dynamics. Trends in Cognitive Sciences, 20(2), 87-95. http://doi.org/10.1016/j.tics.2015.10.004

Beaty, R.E., Benedek M., Kaufman S.B., \& Silvia P.J. (2015). Default and executive Network coupling supports creative idea production. Scientific Reports, 5: 10964. 
doi:10.1038/srep10964.

Beaty, R.E., Silvia P.J., Nusbaum E.C., Jauk E., and Benedek M. (2014). The roles of associative and executive processes in creative cognition. Memory \& Cognition 42: 1186-97. doi:10.3758/s13421-014-0428-8.

Beaty, R. E., Benedek, M., Wilkins, R. W., Jauk, E., Fink, A., Silvia, P. J., et al. (2014). Creativity and the default network: A functional connectivity analysis of the creative brain at rest. Neuropsychologia, 64, 92-98. http://doi.org/10.1016/j.neuropsychologia.2014.09.019

Benedek, M., Jauk, E., Fink, A., Koschutnig, K., Reishofer, G., Ebner, F., \& Neubauer, A. C. (2013). To create or to recall? Neural mechanisms underlying the generation of creative new ideas. NeuroImage, 88, 125-33. http://doi.org/10.1016/j.neuroimage.2013.11.021

Benedek, M., Könen, T., \& Neubauer, A. C. (2012). Associative abilities underlying creativity. Psychology of Aesthetics, Creativity, and the Arts, 6(3), 273-281. http://doi.org/10.1037/a0027059

Benedek, M., \& Neubauer, A. C. (2013). Revisiting Mednick's model on creativity-related differences in associative hierarchies. Evidence for a common path to uncommon thought. The Journal of Creative Behavior, 47(4), 273-289. http://doi.org/10.1002/jocb.35

Binder, J. R., Desai, R. H., Graves, W. W., \& Conant, L. L. (2009). Where is the semantic system? A critical review and meta-analysis of 120 functional neuroimaging studies. Cerebral Cortex, 19(12), 2767-96. http://doi.org/10.1093/cercor/bhp055

Boccia, M., Piccardi, L., Palermo, L., Nori, R., \& Palmiero, M. (2015). Where do bright ideas occur in our brain? Meta-analytic evidence from neuroimaging studies of domain-specific creativity. Frontiers in Psychology, 6. http://doi.org/10.3389/fpsyg.2015.01195

Bowden, E. M., \& Jung-Beeman, M. (2003). Normative data for 144 compound remote associate problems. Behavior Research Methods, Instruments, \& Computers, 35(4), 634-639. http://doi.org/VL - 35

Bowden, E. M., Jung-Beeman, M., Fleck, J., \& Kounios, J. (2005). New approaches to demystifying insight. Trends in Cognitive Sciences, 9(7), 322-328. http://doi.org/10.1016/j.tics.2005.05.012

Brown, A. S. (1973). An empirical verification of Mednick's associative theory of creativity. Bulletin of the Psychonomic Society, 2(6), 429-430.

Bunge, S. A., Wendelken, C., Badre, D., \& Wagner, A. D. (2005). Analogical reasoning and prefrontal cortex: evidence for separable retrieval and integration mechanisms. Cerebral Cortex, 15(3), 239-49.

Cardebat, D., Doyon, B., Puel, M., Goulet, P., \& Joanette, Y. (1990). [Formal and semantic 
lexical evocation in normal subjects. Performance and dynamics of production as a function of sex, age and educational level]. Acta neurologica Belgica, 90(4), 207-217.

Carson, S. H., Peterson, J. B., \& Higgins, D. M. (2005). Reliability, validity, and factor structure of the Creative Achievement Questionnaire. Creativity Research Journal, 17(1), 3750. http://doi.org/10.1207/s15326934crj1701_4

Chavez-Eakle, R. A., Graff-Guerrero, A., García-Reyna, J.-C., Vaugier, V., \& Cruz-Fuentes, C. (2007). Cerebral blood flow associated with creative performance: a comparative study. NeuroImage, 38(3), 519-28. http://doi.org/10.1016/j.neuroimage.2007.07.059

Chen, Q.-L., Xu, T., Yang, W.-J., Li, Y.-D., Sun, J.-Z., Wang, K.-C., et al. (2015). Individual differences in verbal creative thinking are reflected in the precuneus. Neuropsychologia, 75, 441-449. http://doi.org/10.1016/j.neuropsychologia.2015.07.001

Chen, Q., Wei, D., Li, W., Yang, W., Li, H., Lei, Q., et al. (2014). Association of creative achievement with cognitive flexibility by a combined voxel-based morphometry and restingstate functional connectivity study. NeuroImage, 102(2), 474-483. http://doi.org/10.1016/j.neuroimage.2014.08.008

Chermahini, S. A., Hickendorff, M., \& Hommel, B. (2012). Development and validity of a Dutch version of the Remote Associates Task: An item-response theory approach. Thinking Skills and Creativity, 7(3), 177-186. http://doi.org/10.1016/j.tsc.2012.02.003

Christoff, K., Prabhakaran, V., Dorfman, J., Zhao, Z., Kroger, J. K., Holyoak, K. J., \& Gabrieli, J. D. (2001). Rostrolateral prefrontal cortex involvement in relational integration during reasoning. NeuroImage, 14(5), 1136-1149. http://doi.org/10.1006/nimg.2001.0922

Colom, R., Jung, R.E., \& Haier R.J. (2007). General intelligence and memory span: evidence for a common neuroanatomic framework. Cognitive Neuropsychology, 24: 867-78. doi:10.1080/02643290701781557.

Cousijn, J., Zanolie, K., Munsters, R. J. M., Kleibeuker, S. W., \& Crone, E. A. (2014). The relation between resting state connectivity and creativity in adolescents before and after training. PLoS ONE, 9(9), e105780. http://doi.org/10.1371/journal.pone.0105780

Debrenne, M. (2011). Le dictionnaire des associations verbales du français et ses applications. De Deyne, S., Kenett, Y. N., Anaki, D., Faust, M., \& Navarro, D. (in press). Large-scale network representations of semantics in the mental lexicon. In M. N. Jones (Ed.), Big data in cognitive science: From methods to insights. Psychology Press: Taylor \& Francis.

de Souza, L. C., Guimarães, H. C., Teixeira, A. L., Caramelli, P., Levy, R., Dubois, B., \& Volle, E. (2014). Frontal lobe neurology and the creative mind. Psychopathology, 5, 761. http://doi.org/10.3389/fpsyg.2014.00761 
de Souza, L. C., Volle, E., Bertoux, M., Czernecki, V., Funkiewiez, A., Allali, G., et al (2010). Poor creativity in frontotemporal dementia: A window into the neural bases of the creative mind. Neuropsychologia, 48(13), 3733-3742. http://doi.org/10.1016/j.neuropsychologia.2010.09.010

Dietrich, A., \& Kanso, R. (2010). A review of EEG, ERP, and neuroimaging studies of creativity and insight. Psychological Bulletin, 136(5), 822-848. http://doi.org/10.1037/a0019749

Dubois, B., Slachevsky, A., Litvan, I., \& Pillon, B. (2000). The FAB: a Frontal Assessment Battery at bedside. Neurology, 55(11), 1621-1626.

Dumontheil, I., Houlton, R., Christoff, K. \& Blakemore, S.-J. (2010). Development of relational reasoning during adolescence. Developmental Sciences 13, F15-24. http://doi.org/ Eickhoff, S.B., Bzdok, D., Laird, A.R., Kurth, F., \& Fox, P.T. (2012). Activation likelihood estimation meta-analysis revisited. Neuroimage 59, 2349-2361. http://doi.org/10.1016/j.neuroimage.2011.09.017

Eickhoff, S.B., Laird, A.R., Grefkes, C., Wang, L.E., Zilles, K., \& Fox, P.T. (2009). Coordinate-based activation likelihood estimation meta-analysis of neuroimaging data, a random-effects approach based on empirical estimates of spatial uncertainty. Human Brain Mapping, 30, 2907-2926. http://doi.org/10.1002/hbm.20718

Eriksson, S.H., Free, S.L., Thom, M., Symms, M.R., Martinian, L., Duncan, J.S., \& Sisodiya, S.M. (2009). Quantitative grey matter histological measures do not correlate with grey matter probability values from in vivo MRI in the temporal lobe. Journal of Neuroscience Methods, 181(1), 111-118. http://doi.org/10.1016/j.jneumeth.2009.05.001.

e(ye)Brain Inc. (2009). meyeParadigm version 1.7 (Version 1.7). Ivry-sur-Seine, France: e(ye)Brain Inc.

Fink, A., Benedek, M., Koschutnig, K., Pirker, E., Berger, E., Meister, S., et al. (2015). Training of verbal creativity modulates brain activity in regions associated with language- and memory-related demands. Human Brain Mapping, 36(10), 4104-15. http://doi.org/10.1002/hbm.22901

Fink, A., Grabner, R. H., Benedek, M., Reishofer, G., Hauswirth, V., Fally, M., et al. (2009). The creative brain: Investigation of brain activity during creative problem solving by means of EEG and FMRI. Human Brain Mapping, 30(3), 734-748. http://doi.org/10.1002/hbm.20538

Fink, A., Grabner, R. H., Gebauer, D., Reishofer, G., Koschutnig, K., \& Ebner, F. (2010). Enhancing creativity by means of cognitive stimulation: Evidence from an fMRI study. 
NeuroImage, 52(4), 1687-1695. http://doi.org/10.1016/j.neuroimage.2010.05.072

Fink, A., Koschutnig, K., Hutterer, L., Steiner, E., Benedek, M., Weber, B., et al. (2013). Gray matter density in relation to different facets of verbal creativity. Brain Structure and Function, 19(4), 1263-9. http://doi.org/10.1007/s00429-013-0564-0

Folstein, M. F., Folstein, S. E., \& McHugh, P. R. (1975). "Mini-Mental State” - A practical method for grading the cognitive state of patients for the clinician. Journal of Psychiatric Research, 12, 189-198.

Gansler, D. A., Moore, D. W., Susmaras, T. M., Jerram, M. W., Sousa, J., \& Heilman, K. M. (2011). Cortical morphology of visual creativity. Neuropsychologia, 49(9), 2527-2532. http://doi.org/10.1016/j.neuropsychologia.2011.05.001

Genovesio, A., Wise, S. P., \& Passingham, R. E. (2014). Prefrontal-parietal function: from foraging to foresight. Trends in Cognitive Sciences, 18(2), 72-81. http://doi.org/10.1016/j.tics.2013.11.007

Goff, K., \& Torrance, E. P. (2002). The Abbreviated Torrance Test for Adults. IL Scholastic Testing Service.

Goh, S., Bansal, R., Xu, D., Hao, X., Liu, J., \& Peterson, B.S. (2011). Neuroanatomical correlates of intellectual ability across the life span. Developmental Cognitive Neuroscience, 1:305-31 2. doi:10.1016/j.dcn.2011.03.001.

Gonen-Yaacovi, G., de Souza, L. C., Levy, R., Urbanski, M., Josse, G., \& Volle, E. (2013). Rostral and caudal prefrontal contribution to creativity: a meta-analysis of functional imaging data. Frontiers in Human Neuroscience, 7. http://doi.org/10.3389/fnhum.2013.00465

Green, A. E., Cohen, M. S., Raab, H. A., Yedibalian, C. G., \& Gray, J. R. (2015). Frontopolar activity and connectivity support dynamic conscious augmentation of creative state. Human Brain Mapping, 36(3), 923-934. http://doi.org/10.1002/hbm.22676

Green, A. E., Kraemer, D. J. M., Fugelsang, J. A., Gray, J. R., \& Dunbar, K. N. (2010). Connecting long distance: semantic distance in analogical reasoning modulates frontopolar cortex activity. Cerebral Cortex, 20(1), 70-76. http://doi.org/10.1093/cercor/bhp081

Green, A. E., Kraemer, D. J. M., Fugelsang, J. A., Gray, J. R., \& Dunbar, K. N. (2012). Neural correlates of creativity in analogical reasoning. Journal of Experimental Psychology. Learning, Memory, and Cognition, 38(2), 264-72. http://doi.org/10.1037/a0025764

Grogan, A., Green D.W., Ali N., Crinion J.T., \& Price C.J. (2009). Structural Correlates of Semantic and Phonemic Fluency Ability in First and Second Languages. Cerebral Cortex, 19: 2690-98. doi:10.1093/cercor/bhp023.

Guilford, J. P. (1950). Creativity. American Psychologist, 5(9), 444-454. 
http://doi.org/10.1037/h0063487

Gupta, N., Jang, Y., Mednick, S. C., \& Huber, D. E. (2012). The road not taken: creative solutions require avoidance of high-frequency responses. Psychological Science 23(3), 28894. http://doi.org/10.1177/0956797611429710

Haier, R.J., Jung R.E., Yeo R.A., Head K., \& Alkire M.T. (2004). Structural brain variation and general intelligence." NeuroImage, 23: 425-33. doi:10.1016/j.neuroimage.2004.04.025.

Hobeika, L., Diard-Detoeuf, C., Garcin, B., Levy, R. \& Volle, E. (2016). General and specialized brain correlates for analogical reasoning: a meta-analysis of functional imaging studies. Human Brain Mapping, 37, 1953-1969.

Gorno-Tempini, M. L. (2016). Phonological processing in primary progressive aphasia. Journal of Cognitive Neuroscience 28(2), 210-22.http://doi:10-1162/jocn_a_00901

Jauk, E., Neubauer, A. C., Dunst, B., Fink, A., \& Benedek, M. (2015). Gray matter correlates of creative potential: A latent variable voxel-based morphometry study. NeuroImage, 111, 312-320. http://doi.org/10.1016/j.neuroimage.2015.02.002

Jung-Beeman, M., Bowden, E. M., Haberman, J., Frymiare, J. L., Arambel-Liu, S., Greenblatt, R., et al. (2004). Neural activity when people solve verbal problems with insight. PLoS Biology, 2(4), E97. http://doi.org/10.1371/journal.pbio.0020097

Jung, R. E. (2013). The structure of creative cognition in the human brain. Frontiers in Human Neuroscience, 7, 330. http://doi.org/10.3389/fnhum.2013.00330

Jung, R. E., Grazioplene, R., Caprihan, A., Chavez, R. S., \& Haier, R. J. (2010). White matter integrity, creativity, and psychopathology: Disentangling constructs with diffusion tensor imaging. PLoS ONE, 5(3), e9818. http://doi.org/10.1371/journal.pone.0009818

Jung, R. E., Segall, J. M., Bockholt, H. J., Flores, R. A., Smith, S. M., Chavez, R. S., \& Haier, R. J. (2010). Neuroanatomy of creativity. Human Brain Mapping, 31(3), 398-409. http://doi.org/10.1002/hbm.20874

Jung, R. E., Wertz, C. J., Meadows, C. A., Ryman, S. G., Vakhtin, A. A., \& Flores, R. A. (2015). Quantity yields quality when it comes to creativity: a brain and behavioral test of the equal-odds rule. Frontiers in Psychology, 6. http://doi.org/10.3389/fpsyg.2015.00864

Kanai, R., \& Rees, G. (2011). The structural basis of inter-individual differences in human behaviour and cognition. Nature Reviews Neuroscience, 12(4), 231-242. http://doi.org/10.1038/nrn3000

Kenett, Y. N., Anaki, D., \& Faust, M. (2014). Investigating the structure of semantic networks in low and high creative persons. Frontiers in Human Neuroscience, 8, 407. http://doi.org/10.3389/fnhum.2014.00407 
Kounios, J., \& Beeman, M. (2014). The cognitive neuroscience of insight. Annual Review of Psychology, 65(1), 71-93. http://doi.org/10.1146/annurev-psych-010213-115154

Kounios, J., Frymiare, J. L., Bowden, E. M., Fleck, J. I., Subramaniam, K., Parrish, T. B., \& Jung-Beeman, M. (2006). The prepared mind: Neural activity prior to problem presentation predicts subsequent solution by sudden insight. Psychological Science, 17(10), 882-890. http://doi.org/10.1111/j.1467-9280.2006.01798.x

Krawczyk, D. C. (2012). The cognition and neuroscience of relational reasoning. Brain Research, 1428, 13-23. http://doi.org/10.1016/j.brainres.2010.11.080

Krawczyk, D. C., Hanten, G., Wilde, E.A., Li, X., Schnelle, K.P., Merkley, T.L., et al. (2010). Deficits in analogical reasoning in adolescents with traumatic brain injury. Frontiers in Human Neuroscience 4, 62. http://doi.org/10.3389/fnhum.2010.00062.

Kühn, S., Ritter, S. M., Müller, B. C., Baaren, R. B., Brass, M., \& Dijksterhuis, A. (2014). The importance of the default mode network in creativity - a structural MRI study. The Journal of Creative Behavior, 48(2), 152-163.

Laird, A.R., Fox, P.M., Price, C.J., Glahn, D.C., Uecker, A.M., Lancaster, J.L., et al. (2005). ALE meta-analysis, controlling the false discovery rate and performing statistical contrasts. Human Brain Mapping, 25, 155-164. http://doi.org/10.1002/hbm.20136

Li, W., Li, X., Huang, L., Kong, X., Yang, W., Wei, D., et al. (2015). Brain structure links trait creativity to openness to experience. Social Cognitive and Affective Neuroscience, 10(2), 191-8. http://doi.org/10.1093/scan/nsu041

Martindale, C., \& Mines, D. (1975). Creativity and cortical activation during creative, intellectual and eeg feedback tasks. Biological Psychology, 3(2), 91-100. http://doi.org/10.1016/0301-0511(75)90011-3

Mednick, M. T., Mednick, S. A., \& Jung, C. C. (1964). Continual association as a function of level of creativity and type of verbal stimulus. Journal of Abnormal Psychology, 69, 511-515. Mednick, M. T., Mednick, S. A., \& Mednick, E. V. (1964). Incubation of creative performance and specific associative priming. Journal of Abnormal Psychology, 69, 84-88.

Mednick, S. A. (1962). The associative basis of the creative process. Psychological Review, 69, 220-232.

Merck, C., Charnallet, A., Auriacombe, S., Belliard, S., Hahn-Barma, V., Kremin, H., et al. (2011). La batterie d'évaluation des connaissances sémantiques du GRECO (BECSGRECO) : validation et données normatives. Revue de neuropsychologie, 3(4), 235. http://doi.org/10.3917/rne.034.0235

New, B., Pallier, C., Ferrand, L., \& Matos, R. (2001) Une base de données lexicales du 
français contemporain sur internet: LEXIQUE, L'Année Psychologique, 101, 447-462. 1.

New, B., Pallier, C., Brysbaert, M. \& Ferrand, L. (2004). Lexique 2: a new French lexical database. Behavior Research Methods Instruments and Computers,36, 516-524.

Parkin, B. L., Hellyer, P. J., Leech, R., \& Hampshire, A. (2015). Dynamic network mechanisms of relational integration. The Journal of Neuroscience, 35(20), 7660-7673. http://doi.org/10.1523/JNEUROSCI.4956-14.2015

Perrotin, A., Belleville, S., \& Isingrini, M. (2007). Metamemory monitoring in mild cognitive impairment: Evidence of a less accurate episodic feeling-of-knowing. Neuropsychologia, 45(12), 2811-2826. http://doi.org/10.1016/j.neuropsychologia.2007.05.003

Price, A. R., Bonner, M. F., Peelle, J. E. \& Grossman, M. (2015). Converging evidence for the neuroanatomic basis of combinatorial semantics in the angular gyrus. The Journal of Neuroscience, 35: 3276-3284.

Ramnani, N. \& Owen, A. M. (2004). Anterior prefrontal cortex: insights into function from anatomy and neuroimaging. Nat Rev Neurosci 5, 184-94.

Razumnikova, O. M. (2007). Creativity related cortex activity in the remote associates task. Brain Research Bulletin, 73(1-3), 96-102.

Reynolds, J. R., McDermott, K. B. \& Braver, T. S. (2006). A direct comparison of anterior prefrontal cortex involvement in episodic retrieval and integration. Cereb Cortex 16, 519-28. Ridgway, G.R., Henley, S.M.D., Rohrer, J.D., Scahill, R.I., Warren, J.D. \& Fox, N.C. (2008). Ten simple rules for reporting voxel-based morphometry studies. Neuroimage, 40:14291435.

Rojkova, K., Volle, E., Urbanski, M., Humbert, F., Dell'Acqua, F., \& Thiebaut de Schotten, M. (2015). Atlasing the frontal lobe connections and their variability due to age and education: a spherical deconvolution tractography study. Brain Structure and Function. http://doi.org/10.1007/s00429-015-1001-3

Sandkühler, S. \& Bhattacharya, J. (2008). Deconstructing Insight: EEG Correlates of $\begin{array}{lllll}\text { Insightful Problem } & \text { Solving. } & \text { PLOS } & \text { ONE } & \text { 3(1), }\end{array}$ http://doi.org/10.1371/journal.pone.0001459.

Sawyer, K. (2011). The cognitive neuroscience of creativity: A critical review. Creativity Research Journal, 23(2), 137-154. http://doi.org/10.1080/10400419.2011.571191

Shamay-Tsoory, S. G., Adler, N., Aharon-Peretz, J., Perry, D., \& Mayseless, N. (2011). The origins of originality: The neural bases of creative thinking and originality. Neuropsychologia, 49(2), 178-185. http://doi.org/10.1016/j.neuropsychologia.2010.11.020 Smith, K. A., Huber, D. E., \& Vul, E. (2013). Multiply-constrained semantic search in the 
Remote Associates Test. Cognition, 128(1), 64-75. http://doi.org/10.1016/j.cognition.2013.03.001

Stroop, J. R. (1935). Studies of interference in serial verbal reactions. Journal of Experimental Psychology, 18(6), 643-662. http://doi.org/10.1037/h0054651

Subramaniam, K., Kounios, J., Parrish, T. B., \& Jung-Beeman, M. (2011). A brain mechanism for facilitation of insight by positive affect. Journal of Cognitive Neuroscience, 21(3), 415-432. http://doi.org/i: 10.1162/jocn.2009.21057</p>

Takeuchi, H., Taki Y., Hashizume H., Sassa Y., Nagase T., Nouchi R. \& Kawashima R. (2012). The Association between Resting Functional Connectivity and Creativity." Cerebral Cortex, 22: 2921-29. doi:10.1093/cercor/bhr371.

Takeuchi, H., Taki, Y., Sassa, Y., Hashizume, H., Sekiguchi, A., Fukushima, A., \& Kawashima, R. (2010a). Regional gray matter volume of dopaminergic system associate with creativity: Evidence from voxel-based morphometry. NeuroImage, 51(2), 578-85. http://doi.org/10.1016/j.neuroimage.2010.02.078

Takeuchi, H., Taki, Y., Sassa, Y., Hashizume, H., Sekiguchi, A., Fukushima, A., \& Kawashima, R. (2010b). White matter structures associated with creativity: Evidence from diffusion tensor imaging. NeuroImage, 51(1), 11-18. http://doi.org/10.1016/j.neuroimage.2010.02.035

Thiebaut de Schotten, M., Tomaiuolo, F., Aiello, M., Merola, S., Silvetti, M., Lecce, F., et al. (2014). Damage to white matter pathways in subacute and chronic spatial neglect: A group study and 2 single-case studies with complete virtual "in vivo" tractography dissection. Cerebral Cortex, 24(3), 691-706. http://doi.org/10.1093/cercor/bhs351

Topolinski, S., \& Reber, R. (2010). Gaining insight into the "Aha" experience. Current Directions in Psychological Science, 0, 1-4.

Torrance, E. P. (1972). Predictive validity of the Torrance tests of creative thinking. The Journal of Creative Behavior, 6(4), 236-262. http://doi.org/10.1002/j.21626057.1972.tb00936.x

Turkeltaub, P.E., Eickhoff, S.B., Laird, A.R., Fox, M., Wiener, M., \& Fox, P. (2012). Minimizing within-experiment and within-group effects in Activation Likelihood Estimation meta-analyses. Human Brain Mapping, 33, 1-13. http://doi.org/10.1002/hbm.21186

Urbanski, M., Bréchemier, M.-L., Garcin, B., Bendetowicz, D., Foulon, C., Thiebaut de Schotten, M., Rosso, C., Clarençon, F., Dupont, S., Pradat-Diehl, P., Labeyrie, M.A., Levy, R., \& Volle, E. (2016). Reasoning by analogy requires the left frontal pole: lesion-deficit mapping and clinical implications. Brain 139, 1783-99. http://doi.org/10.1093/brain/aww072 
Vartanian, O. (2009). Variable attention facilitates creative problem solving. Psychology of Aesthetics, Creativity, and the Arts, 3, 57-59.

Vartanian, O., Martindale, C., \& Matthews, J. (2009). Divergent thinking ability is related to faster relatedness judgments. Psychology of Aesthetics, Creativity, and the Arts, 3(2), 99-103. http://doi.org/10.1037/a0013106

Vigneau, M., Beaucousin, V., Hervé, P.-Y., Jobard, G., Petit, L., Crivello, F., et al. (2010). What is right-hemisphere contribution to phonological, lexico-semantic, and sentence processing?: Insights from a meta-analysis. NeuroImage, 54(1), 577-93. http://doi.org/10.1016/j.neuroimage.2010.07.036

Volle, E., Gilbert, S. J., Benoit, R. G., \& Burgess, P. W. (2010). Specialization of the rostral prefrontal cortex for distinct analogy processes. Cerebral Cortex, 20:2647-2659. http://doi.org/10.1093/cercor/bhq012

Weisberg, R. W. (2013). On the "demystification" of insight: A critique of neuroimaging studies of insight. Creativity Research Journal, 25(1), 1-14. http://doi.org/10.1080/10400419.2013.752178

Wei, T., Liang, X., He, Y., Zang, Y., Han, Z., Caramazza, A., \& Bi, Y. (2012). Predicting conceptual processing capacity from spontaneous neuronal activity of the left middle temporal gyrus. The Journal of Neuroscience, 32(2), 481-489. http://doi.org/10.1523/JNEUROSCI.1953-11.2012

Wu, X., Yang, W., Tong, D., Sun, J., Chen, Q., Wei, D., et al. (2015). A meta-analysis of neuroimaging studies on divergent thinking using activation likelihood estimation. Human Brain Mapping, 36(7), 2703-18. http://doi.org/10.1002/hbm.22801

Zhu, F., Zhang, Q., \& Qiu, J. (2013). Relating inter-individual differences in verbal creative thinking to cerebral structures: An optimal voxel-based morphometry study. PLoS ONE, 8(11), e79272. http://doi.org/10.1371/journal.pone.0079272 
Table 1. Main characteristics, general psychometric, and creativity scores of the participants ( $\mathbf{n}=\mathbf{5 4} ; 27$ females). Only RTs for correct responses were considered.

\begin{tabular}{|c|c|c|c|c|c|}
\hline & Mean & $(S D)$ & Min & - & Max \\
\hline Age (years) & 45.8 & $(14.4)$ & 22 & - & 71 \\
\hline Educational level (years) & 15.4 & $(3.0)$ & 10 & & 26 \\
\hline $\mathrm{FAB}(/ 18)$ & 16.7 & $(1.2)$ & 13 & & 18 \\
\hline Categorical fluency & 38.1 & $(8.8)$ & 21 & & 62 \\
\hline Literal fluency & 26.9 & $(8.1)$ & 12 & - & 42 \\
\hline Stroop interference & 4.5 & $(8.0)$ & -17.3 & - & 20.9 \\
\hline CAT-solving (\%) & 48.3 & (8.9) & 29.2 & - & 66.7 \\
\hline CAT-solving-RT (sec.) & 6.5 & (1.6) & 3.6 & - & 10.9 \\
\hline CAT-solving-RT in Eureka trials (sec.) & 5.8 & (1.4) & 3.1 & - & 9.3 \\
\hline CAT-solving-RT in non-Eureka trials (sec.) & 13.1 & (4.9) & 5.5 & - & 27.9 \\
\hline CAT-index & 21 & $(11.8)$ & -3 & - & 50 \\
\hline CAT-eureka (\%) & 88.7 & $(9.1)$ & 59.1 & - & 100 \\
\hline CAT-eval (\%) & 79.4 & $(9.4)$ & 55.8 & - & 97.1 \\
\hline CAT-eval-RT (sec.) & 3.3 & $(.9)$ & 1.9 & - & 5.8 \\
\hline ATTA index & 66.2 & $(8.6)$ & 47 & - & 86 \\
\hline ATTA originality (raw) & 7.8 & $(3.6)$ & 1 & - & 15 \\
\hline ATTA fluency (raw) & 11.8 & $(5.3)$ & 1 & - & 31 \\
\hline CAQ score & 9 & $(12.4)$ & 0 & - & 72 \\
\hline
\end{tabular}


Table 2. Main characteristics and comparison of Close and Distant CAT trials.

* Mean lexical frequencies represent the average number of occurrences per million in Lexique corpuses.

\section{Close CAT Distant CAT $\quad$ Statistical comparison between \\ Mean (SD) Mean (SD) close and distant}

\begin{tabular}{|c|c|c|c|}
\hline \multicolumn{4}{|l|}{ CAT properties } \\
\hline Number of trials & 36 & 36 & - \\
\hline $\begin{array}{l}\text { Mean association strength } \\
\text { (between cue-words and solution } \\
\text { word) }\end{array}$ & $14.74(6.82)$ & $3.52(1.66)$ & $\begin{array}{l}\mathrm{U}=0 \\
\mathrm{P}<.001\end{array}$ \\
\hline Mean steepness of the cue-words & $2.55(1.14)$ & $2.67(1.76)$ & $\begin{array}{l}\mathrm{U}=627.5 \\
\mathrm{P}=.817\end{array}$ \\
\hline $\begin{array}{l}\mathrm{Nb} \text { of noun/verb/adjectives } \\
\text { among cue-words }\end{array}$ & $57 / 44 / 7$ & $70 / 30 / 8$ & - \\
\hline $\begin{array}{l}\text { Mean lexical frequency of } \\
\text { solution words* }\end{array}$ & $120.5(118.4)$ & $111.1(114.7)$ & $\begin{array}{l}\mathrm{U}=636.0 \\
\mathrm{P}=.892\end{array}$ \\
\hline $\begin{array}{l}\text { Mean lexical frequency of the } \\
\text { evaluation test words* }\end{array}$ & $190.7(311.1)$ & $120.1(129.4)$ & $\begin{array}{l}\mathrm{U}=575.0 \\
\mathrm{P}=.411\end{array}$ \\
\hline \multicolumn{4}{|l|}{ Performance of the participants } \\
\hline $\begin{array}{l}\text { CAT-solving } \\
\text { (Accuracy in \%) }\end{array}$ & $58.2(10.6)$ & $38.4(9.9)$ & $\begin{array}{l}\mathrm{t}(53)=14.4 \\
\mathrm{P}<.001\end{array}$ \\
\hline $\begin{array}{l}\text { CAT-solving-RT (sec.) } \\
\text { for correct solving }\end{array}$ & $6.1(1.4)$ & $7.2(2.2)$ & $\begin{array}{l}t(53)=-4.8 \\
P<.001\end{array}$ \\
\hline $\begin{array}{l}\text { CAT-eureka if correct solving } \\
\text { (Accuracy in \%) }\end{array}$ & $91.3(8.5)$ & $84.7(12.8)$ & $\begin{array}{l}\mathrm{t}(53)=4.6 \\
\mathrm{P}<.001\end{array}$ \\
\hline $\begin{array}{l}\text { CAT-eval if incorrect solving } \\
\text { (Accuracy in \%) }\end{array}$ & $84.0(8.3)$ & $76.6(12.7)$ & $\begin{array}{l}\mathrm{t}(53)=4.4 \\
\mathrm{P}<.001\end{array}$ \\
\hline
\end{tabular}


Table 3. Significant results of the VBM analysis.

Significant anatomical regions for the whole brain analysis and after small volume correction (SVC) are reported, including Brodmann areas and MNI peak coordinates. SVC analyses were thresholded at a $\mathrm{p}<.05$ corrected for family wise errors (FWE).

IPL: inferior parietal lobule; rlPFC: rostrolateral prefrontal cortex.

\begin{tabular}{|l|c|c|c|c|c|c|c|}
\hline \multicolumn{1}{|c|}{ Brain region } & BA & \multicolumn{3}{|c|}{$\begin{array}{c}\text { MNI peak } \\
\text { coordinates }\end{array}$} & \multicolumn{1}{c|}{$\begin{array}{c}\text { SVC analysis } \\
\text { FWE corrected }\end{array}$} \\
\hline & & $\mathbf{x}$ & $\mathbf{y}$ & $\mathbf{z}$ & $\begin{array}{c}\text { T } \\
\text { score }\end{array}$ & Cluster size & P values \\
\hline CAT-solving - negative correlation & & & & & & \\
\hline left-rlPFC & $47 / 46 / 10$ & -39 & 45 & 1 & 4.32 & 144 & .043 \\
\hline left-IPL & 40 & -51 & -33 & 45 & 4.53 & 86 & .024 \\
\hline
\end{tabular}




\section{ACCEPTED MANUSCRIPT}

Table 4. Probability of connectivity of the VBM clusters, computed on the white matter tracts available in the BCB toolkit and described in Rojkova et al., 2014. VBM clusters are regions in which GM volume correlated with CAT-solving performance. Probabilities lower than .5 are not shown and were not considered. All the reported results are in the left hemisphere. AF: Arcuate fasciculus (anterior segment); ATR: anterior thalamic radiations; FMT: fronto-marginal tract; FSP: frontostriatal projections; IFOF: Inferior Fronto-Occipital fasciculus; IPL: inferior parietal lobule; rlPFC: rostrolateral prefrontal cortex; SLF: Superior Longitudinal fasciculus; UF: Uncinate Fasciculus.

\begin{tabular}{|l|l|l|}
\hline & rIPFC & IPL \\
\hline ATR & .98 & \\
\hline FSP & .94 & \\
\hline FMT & .50 & \\
\hline IFOF & .92 & \\
\hline UF & .66 & \\
\hline SLF3 & .86 & .90 \\
\hline AF & & .80 \\
\hline
\end{tabular}




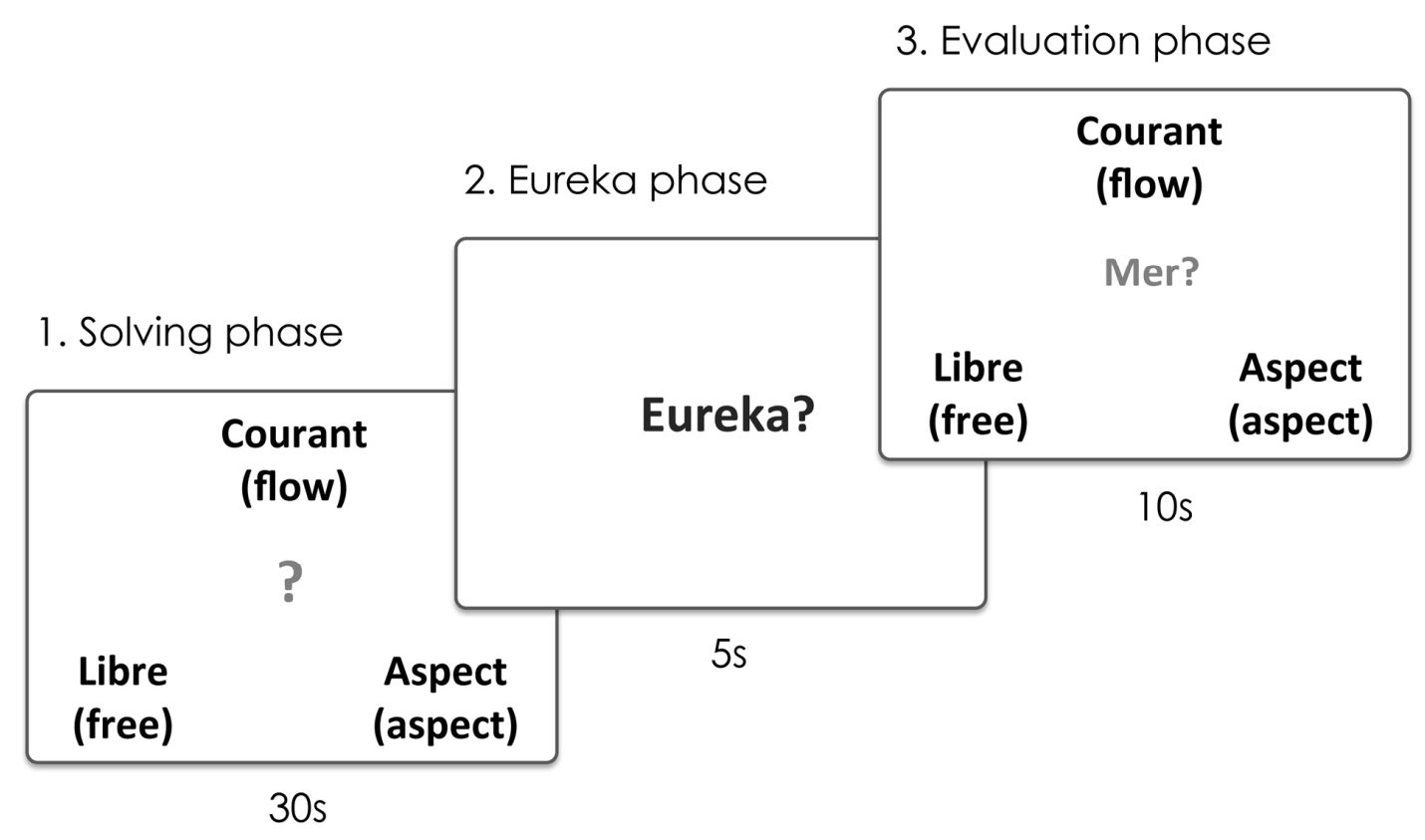




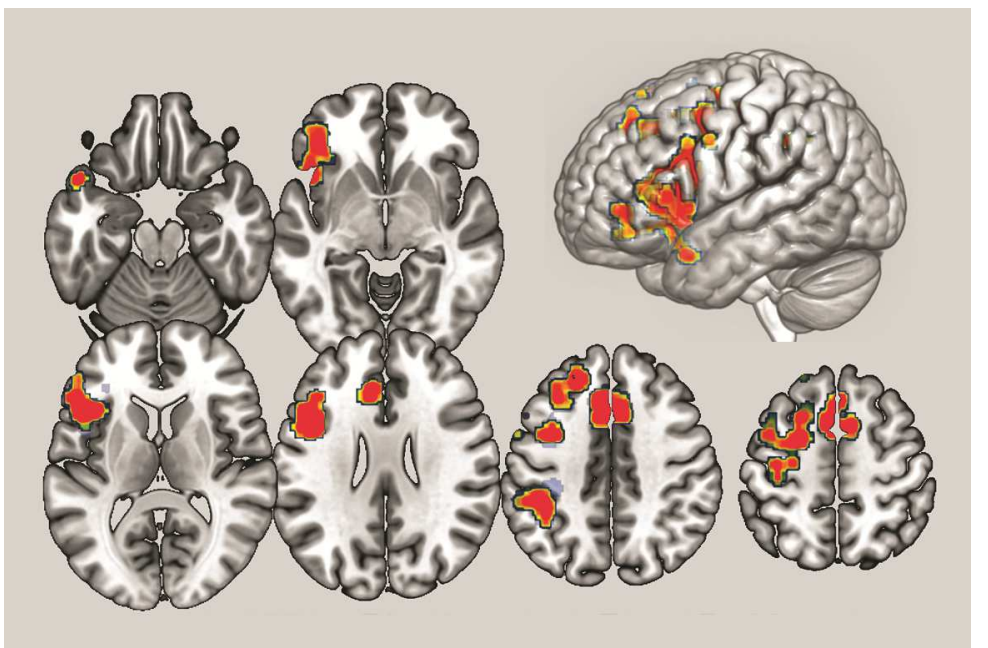




\section{CAT-solving}

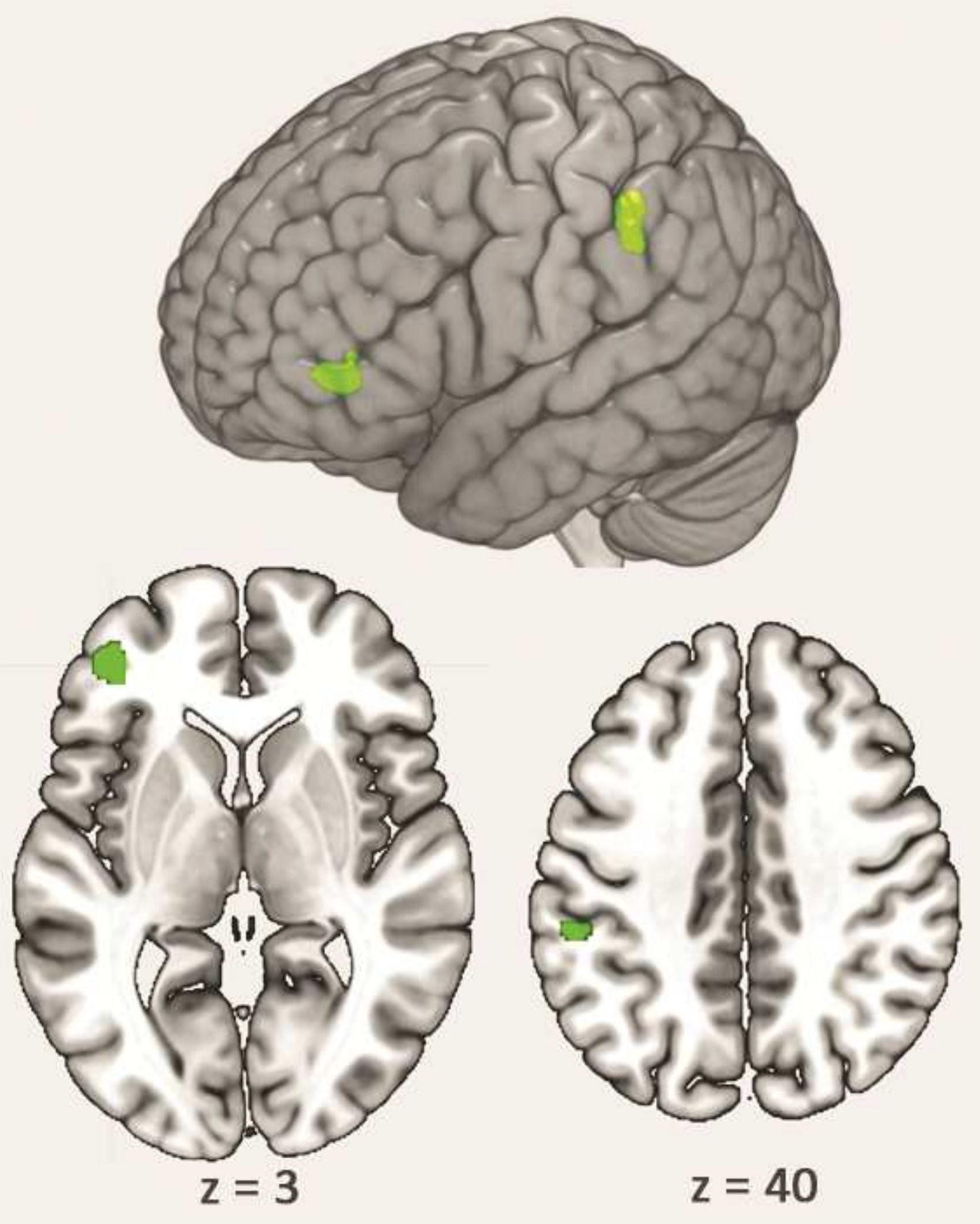




\section{Highlights}

- Individual variability in the ability to combine remote ideas reflects creative potential

- A creative combination task in which semantic distance between words vary is proposed

- Performance at this task is associated with structural variations in left rostral frontal and posterior parietal regions

- These regions are connected through white matter tracts

- The ability to combine distant information into new ways rely on brain morphometry 